\title{
Suggested strategies to reduce the carbon footprint of anesthetic gases in the operating room
}

\author{
Antonio Caycedo-Marulanda, MD, MSc, FRCS, FACS, FASCRS $\mathbb{1} \cdot$ Sanjiv Mathur, MD, FRCPS $\mathbb{D}$
}

Received: 22 April 2021 / Revised: 9 August 2021/Accepted: 23 September 2021/Published online: 18 October 2021

(c) Canadian Anesthesiologists' Society 2021

Keywords carbon pricing - anesthetic gases . forcing functions

To the Editor,

The World Health Organization has declared climate change as the greatest threat to global health in the $21 \mathrm{st}$ century. ${ }^{1}$ All physicians should consider reducing their carbon footprint in their clinical settings. It is well established that volatile anesthetics are potent greenhouse gases (GHG) and that desflurane is responsible for a significant portion of the carbon footprint of the operating theatre. ${ }^{2}$ We proposed to implement a strategy to make a tertiary care centre in Ontario (Health Sciences North [HSN], Sudbury, ON, Canada) desflurane-free to reduce the carbon footprint of the facility. We implemented an approach supporting the use of forcing functions according to a "hierarchy of effectiveness" as various studies have shown that relying on educational interventions to change clinicians' behaviours is predictably disappointing. ${ }^{3}$

In 2016, we presented evidence of the increased carbon footprint of desflurane at HSN during anesthesia rounds and at the resident journal club. One of the authors (S.M.) made multiple presentations at national and international academic meetings (those of the Canadian

\footnotetext{
A. Caycedo-Marulanda, MD, MSc, FRCS, FACS, FASCRS Department of Surgery, Kingston General Hospital, Queen's University, Kingston, ON, USA

S. Mathur, MD, FRCPS ( $\square)$

Department of Anesthesiology and Critical Care, Health Sciences North, Northern Ontario School of Medicine, Sudbury, ON, Canada

e-mail: Scns_mathur@icloud.com
}

Anesthesiologists' Society, American Society of Anesthesiologists, and International Anesthesia Research Society) as well as to multiple departments of anesthesiology across Canada; this added credibility to the message and promoted discussion among physicians nationally. Educational sessions including hospital leadership and HSN grand rounds completed the "educational program" of the interventions.

"Medium leverage" interventions were employed with warning stickers about carbon intensity placed on desflurane vaporizers. In 2019, a "high leverage" approach was used with the removal of the desflurane vaporizer from the anesthesia machine and placing it in a designated area outside of individual operating rooms. Physicians were required to sign out desflurane from a secure system $\left[\right.$ Pyxis $^{\mathrm{TM}}$ ] and install the vaporizer themselves. Finally in 2020, we implemented a forcing function by removing desflurane from the formulary at HSN. The implementation of these measures was associated with a significant drop in carbon dioxide equivalents (CDE) (Figure 1) and kilometre driving equivalents from the HSN volatile gases use. The 2016 CDE were: sevoflurane, 31 tonnes vs desflurane, 744 tonnes; the 2019 CDE were: sevoflurane, 66 tonnes vs desflurane, 140 tonnes; and the $2020 \mathrm{CDE}$ were: sevoflurane, 52 tonnes $v s$ desflurane, 0 tonnes. It should be noted that the number of anesthesia cases dropped in 2020 because of the COVID-19 pandemic. The CDE were calculated using the Yale Gassing Greener program ${ }^{\mathrm{A}}$ and verified by our own calculations manually using wellestablished tables published by Andersen et al. ${ }^{2}$ Avoiding

\footnotetext{
A Yale Gassing Greener program. Available from URL: https://apps. apple.com/us/app/yale-gassing-greener/id1152700062 (accessed September 2021).
} 


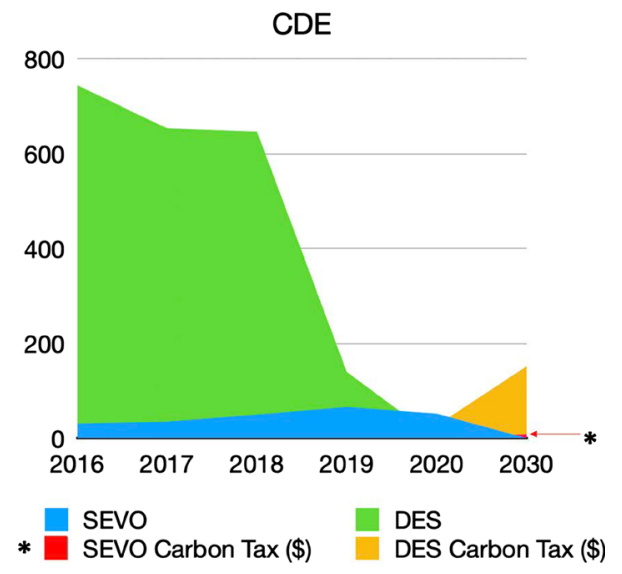

FIGURE 1 The graph compares the annual carbon dioxide equivalence (CDE) from sevoflurane (SEVO) and desflurane (DES) from Health Sciences North (HSN) (Sudbury, ON) from 2016 to 2020. The effect of the Canadian carbon tax is depicted from 2019 to 2030. (*) Represents the tax increase for SEVO as its graphical depiction is miniscule. Please refer to letter for values.

desflurane did not change morbidity or mortality when we studied one surgical procedure ${ }^{4}$ however, this requires further investigation. The observed increase in sevoflurane use suggests that desflurane users converted to sevoflurane rather than employing other strategies (total intravenous anesthesia, regional anesthesia), which may have reduced the carbon footprint.

Interestingly, implementing carbon pricing is an effective strategy to reduce carbon pollution. ${ }^{\mathrm{B}}$ Thus, the existing Canadian carbon price of $30 \mathrm{CAD} /$ tonne $\mathrm{CDE}$ (price in 2020 at the time of study completion) ${ }^{5}$ if applied to volatile anesthetic gases would increase prices by 1.48 CAD per bottle of sevoflurane and by $26.82 \mathrm{CAD}$ per bottle of desflurane. In 2030, the projected carbon price of 170 $\mathrm{CAD} /$ tonne $\mathrm{CDE}$ would increase the price of sevoflurane by $8.39 \mathrm{CAD}$ and the price of desflurane by $151.98 \mathrm{CAD}$ (Figure 1). This will essentially make the purchase of desflurane difficult to justify. Unfortunately, volatile anesthetics are currently not included in the GHG Canadian inventory and not yet included in the carbon pricing. We have lobbied Canadian politicians to include volatile anesthetics in the inventory and pricing mechanism. We also remind readers of the potential importance of reducing their carbon footprint by other practices, including "avoid, reduce, reuse, recycle, and reprocess".

Implementing a carbon price on anesthetic gases could be an effective strategy to further reduce the carbon footprint of operating rooms across the planet.

Disclosures None.

Funding statement None.

Editorial responsibility This submission was handled by Dr. Stephan K.W. Schwarz, Editor-in-Chief, Canadian Journal of Anesthesia/Journal canadien d'anesthésie.

\section{References}

1. World Health Organization. COP24 Special Report Health \& Climate Change; 2018: 1-74. Available from URL: https://apps. who.int/iris/bitstream/handle/10665/276405/9789241514972-eng. pdf? sequence=1\&isAllowed=y (accessed September 2021).

2. Andersen MP, Nielsen OJ, Wallington TJ, Karpichev B, Sander S. Assessing the impact on global climate from general anesthetic gases. Anesth Analg 2012; 114: 1081-5.

3. Soong $C$, Shojania $K G$. Education as a low-value improvement intervention: often necessary but rarely sufficient. BMJ Qual Saf 2020; 29: 353-7.

4. Caycedo-Marulanda, A, Caswell J, Mathur S. Comparing the environmental impact of anesthetic gases during transanal total mesorectal excision surgery at a tertiary healthcare centre. Can J Anesth 2020; 67: 607-8.

5. Sawyer D, Stiebert S, Gignac R, Campney A, Beugin D. 2020 Expert Assessment of Carbon Pricing Systems. Canadian Institute for Climate Choices. Environment and Climate Change Canada. Available from URL: https://publications.gc.ca/collections/ collection_2021/eccc/En4-434-2021-eng.pdf (accessed September 2021).

Publisher's Note Springer Nature remains neutral with regard to jurisdictional claims in published maps and institutional affiliations.

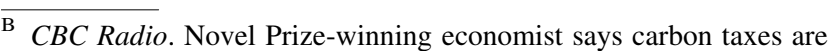
the solutions to climate change. October 8, 2018). Available from URL: https://www.cbc.ca/radio/asithappens/as-it-happens-mondayedition-1.4843029/nobel-prize-winning-economist-says-carbon-taxesare-the-solution-to-climate-change-1.4854639 (accessed September 2021).
} 